doi: $10.2306 /$ scienceasia1513-1874.2013.39.527

\title{
Centrifuge simulation of LNAPL transportation in sand deposits with containment under flow and no-flow conditions
}

\author{
Chusak Kererat $^{\mathrm{a}, *}$, Suttisak Soralump ${ }^{\mathrm{b}}$, Inthuorn Sasanakul ${ }^{\mathrm{c}}$ \\ a Department of Civil Engineering, Faculty of Engineering, \\ Rajamangala University of Technology Rattanakosin (RMUTR), Prachuap Khiri Khan 77110 Thailand \\ b Department of Civil Engineering, Faculty of Engineering, Kasetsart University, Jatujak, \\ Bangkok 10900 Thailand \\ c Centre of Earthquake Engineering Simulation, Geotechnical Centrifuge Research Centre, \\ Rensselaer Polytechnic Institute, Troy, New York 12180 USA
}

*Corresponding author, e-mail: Chusak.K@rmutr.ac.th

\begin{abstract}
Light nonaqueous phase liquid (LNAPL) contamination of subsoil is a serious problem affecting human health and disturbing the environment. This paper describes centrifuge tests of LNAPL migration in a sandy soil layer that were focused on a soil-cement barrier as a containment to protect the groundwater from contamination. Two centrifuge tests were performed in this study for the following two scenarios: groundwater flow and no groundwater flow conditions. Liquid paraffin oil was used to represent LNAPL, and it was infiltrated into the partially saturated sand deposit. The centrifuge tests were performed at $30 \mathrm{~g}$, and pore pressure sensors and camera recordings were used to evaluate the model behaviour. The results show that groundwater flow accelerates LNAPL migration in sandy soil. In addition, LNAPL was found to migrate below the groundwater level, and the soil-cement barrier was found to serve effectively for containment.
\end{abstract}

KEYWORDS: centrifuge test, LNAPL migration, sandy soil, soil cement barrier

\section{INTRODUCTION}

Subsurface contamination is a major public-health problem that causes environmental damage. Sources of groundwater contaminants include gas stations, chemical manufacturing, processing facilities, and other facilities that have underground storage tanks (USTs) to store hazardous chemicals. Many USTs that have reached or exceeded their useful lives are at risk of leaking toxic constituents. Petroleum hydrocarbons leaking from USTs, commonly found in soils and in shallow groundwater, are potentially carcinogenic to humans. They are nearly immiscible in water and are thus referred to as nonaqueous phase liquids (NAPLs). LNAPLs that have densities less than that of water always travel through the unsaturated zone of subsurface soil and move downward under gravitational force. If a small volume of LNAPLs is released into the subsoil, it will be retained by capillary forces in the soil pores and may spread laterally until movement ceases. If sufficient LNAPL is released, it may not only be retained in the soil pores but may also depress the capillary fringe and water table. Many remediation methods have been proposed to control leaks from USTs and to minimize the risks to human health and the environment. One of these is containment, which is the focus of this study.

Previous studies of LNAPL migration in subsurface soil have included laboratory studies, numerical simulations, and field investigations ${ }^{1-7}$. All of these approaches have their limitations. The geotechnical centrifuge modelling technique is a great alternative because centrifuge acceleration can simulate the field stress levels in a small model and shorten the experimental time. The scale model tested in geotechnical centrifuge modelling can be extended to a prototype scale using scaling laws. Scaling laws have been developed and validated by several researchers to use in pollutant transport problems. Three basic parameters always involved in scaling laws are length, time, and mass. Length is scaled in the centrifuge by $1 / N$, time by $1 / N^{2}$, and mass by $1 / N^{3}$, where $N$ represents the earth gravity ${ }^{8-13}$.

This paper describes LNAPL migration in a sandy soil layer contained by soil-cement barriers under conditions of groundwater flow and no-groundwater 


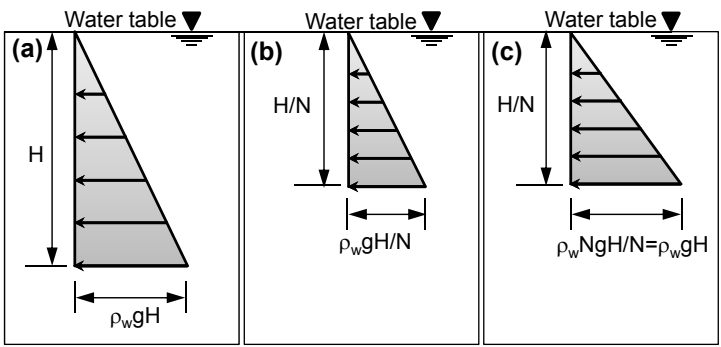

Fig. 1 Pressure distribution: (a) prototype under the gravity field of the earth, (b) 1-g model under the earth's gravity field: $1 g$, and (c) centrifuge model under acceleration gravity field: $N g$.

flow. Two experiments were designed to represent the hydrogeology in fields due to seasonal changes in Thailand, namely, the hot, rainy, and cool seasons. The first test was performed under no-groundwaterflow conditions, representing the soil layer in the hot and cool seasons. The second test was designed to represent the soil layer in the rainy season, when water is likely to flow to reach water sources such as a pumping well or a river. Pore pressure sensors are installed in the centrifuge model at various locations to monitor changes in water pressure during the experiments, and on-board cameras are installed to record LNAPL migration during the tests

\section{MATERIALS AND METHODS}

\section{Principle of centrifuge test}

The basic principle of centrifuge testing consists of creating stress conditions which are similar to those applied to gravity in the field to a prototype, in or on model, with dimension which are much smaller than those of the prototype. Centrifugal force which is the apparent outward force that draws a rotating body away from the centre of rotation acts on the model. This can be achieved by placing the model in the basket at the end of centrifuge boom, then subjecting it to an initial acceleration field. If a centrifuge model in which the geometry is linearly reduced by a factor of $N$ from the corresponding prototype dimensions experiences a centrifugal force of $\mathrm{Ng}$, the product of depth and acceleration becomes the same in the model and the prototype. Thus (Fig. 1), the water pressure in the model will be identical to those in the prototype. As a result, the self-weight effects on the prototype can be simulated in the centrifuge model but not the $1-g$ model $^{14,15}$.

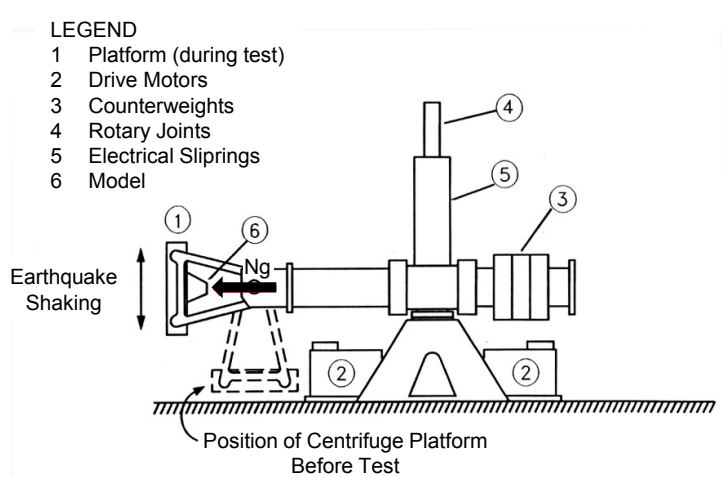

Fig. 2 Sketch of the RPI geotechnical centrifuge (adapted from www.rpi.edu/ dobryr/sketch.html).

\section{Centrifuge model}

Two centrifuge tests were performed at 30 times the gravitational force using the geotechnical centrifuge laboratory at the Rensselaer Polytechnic Institute (RPI) in Troy, NY. The sketch of RPI geotechnical centrifuge is shown in Fig. 2. This centrifuge has a normal radius of $2.7 \mathrm{~m}$, which was the distance between the centre of the payload and the centrifuge axis. Its payload capacity is $150 \mathrm{~g}$ ton, with a maximum acceleration of $160 \mathrm{~g}$. The strong box used in the experiments has internal dimensions of $0.37 \mathrm{~m}$ in width, $0.88 \mathrm{~m}$ in length and $0.36 \mathrm{~m}$ in height (the prototype is $11.10 \mathrm{~m}$ wide, $26.40 \mathrm{~m}$ long and $10.80 \mathrm{~m}$ high).

Schematics of the models are shown in Fig. 3a

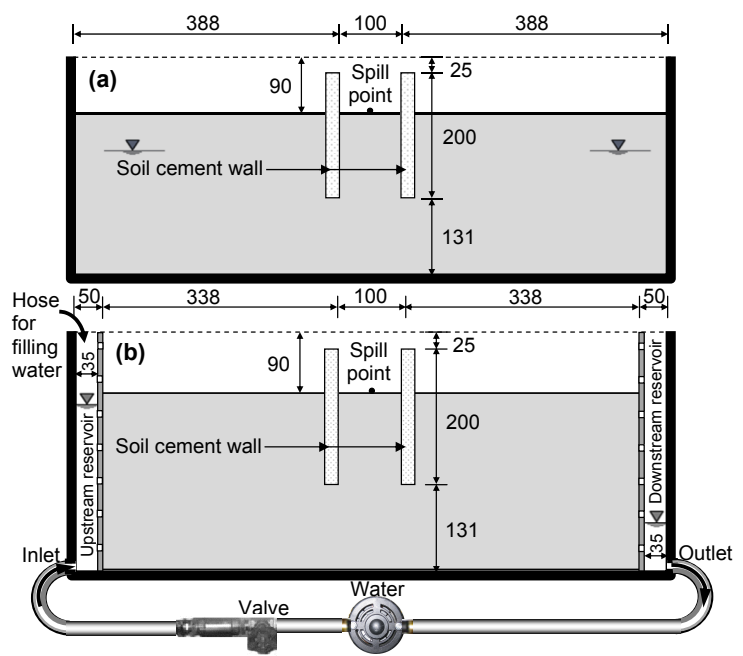

Fig. 3 Schematic diagram of strongbox (model unit: $\mathrm{mm}$ ): (a) no groundwater flow, and (b) groundwater flow. 


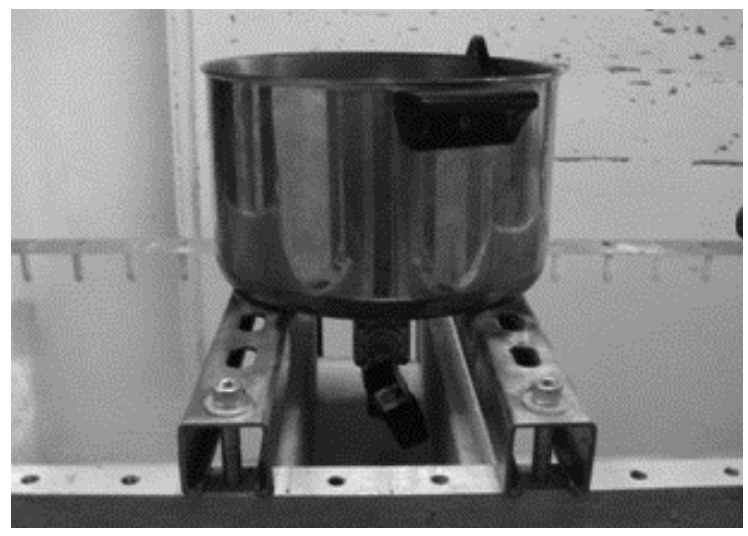

Fig. 4 LNAPL container.

and Fig. $3 \mathrm{~b}$ for the tests with flow and no flow, respectively. The strong box consists of a 0.05 -m-thick front wall made of Plexiglas for viewing and a 0.025$\mathrm{m}$-thick aluminium plate for the other sides. Fig. 3b shows how the box was divided into 3 sections by two 0.0127-m-thick perforated walls made of aluminium covered by geotextile. The sand deposit was contained in the central section of the strongbox. The two side sections were used as water reservoirs to control the water table at the boundaries of the soil sample. To maintain flow along the length of the model, it was necessary to maintain a differential pressure. This was accomplished by creating vertical reservoirs on each end of the model. The wall of the reservoir in contact with the soil was perforated with many small holes to allow water to flow freely and evenly into the soil. A pump system was developed to collect water from the low-pressure reservoir (downstream), and return it to the high-pressure supply reservoir (upstream). The flow rate of the pump was adjustable to allow setting of the desired pressure differential in the two reservoirs, thereby controlling the groundwater flow within the model. Additionally, a separate water supply hose was installed in the high-pressure reservoir. The purpose of this supply was to add water to the model to offset the loss of water in the model caused by evaporation during the test.

A special spill system was developed for these centrifuge experiments. It was composed of the following two parts: a container and a spill system. The container dimensions were $0.28 \mathrm{~m}$ in diameter and $0.15 \mathrm{~m}$ in height, which allowed it to contain $2000 \mathrm{ml}$ of LNAPL (compared to the prototype, which was calculated by using scaling law of mass, $1 / N^{3}$, could contain 54000 litres). The container was welded to Ushaped steel bars that could be mounted on the top of the strong box by bolts (Fig. 4). The container itself was designed to have a large diameter and minimal height to minimize the change in the flow rate through the orifice as the head in the container diminished. This system was tested extensively with various sizes and numbers of orifice holes to yield the desired flow rate.

\section{Materials preparations and instrumentation}

The sandy soil used in this study was Nevada sand, which is silica sand with a particle density of $2650 \mathrm{~kg} / \mathrm{m}^{3}$, a maximum dry density of $1709.14 \mathrm{~kg} / \mathrm{m}^{3}$, a minimum dry density of $1513.74 \mathrm{~kg} / \mathrm{m}^{3}$ and a hydraulic conductivity range of $4.75 \mathrm{~m} /$ day to $1.99 \mathrm{~m} /$ day, depending on its relative density. Nevada sand is a uniformly graded soil with a mean grain size $\left(D_{50}\right)$ of $0.15 \mathrm{~mm}$. The coefficient of uniformity $\left(C_{\mathrm{u}}\right)$ and the coefficient of curvature $\left(C_{\mathrm{c}}\right)$ of Nevada sand are 2.056 and 0.894 , respectively. In this experiment, the desired dry density of the soil was $1600 \mathrm{~kg} / \mathrm{m}^{3}$ which was the general dry density of sandy soil, a relative density of $50 \%$ and a porosity of approximately $40 \%$. The saturated hydraulic conductivity used for this sand was $5.6 \times 10^{-3} \mathrm{~cm} / \mathrm{s}$.

The soil-cement sample used as a barrier was $0.02 \mathrm{~m}$ thick, $0.37 \mathrm{~m}$ wide and $0.20 \mathrm{~m}$ deep, with a dry density of $1740 \mathrm{~kg} / \mathrm{m}^{3}$. The mix proportions were calculated using a water-cement ratio $(w / c)$ of 2 and a cement content of $220 \mathrm{~kg} / \mathrm{m}^{316}$. After mixing, two soil cement walls were constructed within the strongbox by casting the walls in place. Both ends of the soil cement wall were adhered to a rubber sheet and fixed to the side walls of the strongbox. This procedure was setup to make sure there were no leaks from barrier interfaces. The LNAPL used in this experiment was paraffin liquid selected for its very low volatility at room temperature, its negligible solubility in water, and its safety ${ }^{17}$. To enhance the intensity of the paraffin red colour, Sudan IV (Scholar Chemistry, USA) was used as a dye at a ratio of $0.1 \%$ by weight ${ }^{18}$. The properties of paraffin liquid, Sudan IV, and water are summarized in Table 1. According to the properties of paraffin liquid, the mass of the dissolved and evaporation LNAPL is no effect to the migration of LNAPL in both the cases.

The sand deposit was placed in the strongbox from a constant height using pluviation, also known as sand raining. Sand was poured in the top opening, and a device was moved in a smooth motion back and forth across the box to let the sand fall evenly into the box. This preparation was divided into eight layers, and each layer was pluviated lift by lift. The density of the sand in each lift was verified to ensure that the 
Table 1 Properties of paraffin liquid, Sudan IV, and water.

\begin{tabular}{|c|c|c|c|}
\hline & Liquid paraffin & Sudan IV & Water \\
\hline Formula & $\mathrm{C}_{20} \mathrm{H}_{42}$ (Above) & $\mathrm{C}_{24} \mathrm{H}_{20} \mathrm{~N}_{4} \mathrm{O}$ & $\mathrm{H}_{2} \mathrm{O}$ \\
\hline Appearance & $\begin{array}{l}\text { Colorless, } \\
\text { odorless }\end{array}$ & $\begin{array}{l}\text { Dark brown } \\
\text { powder }\end{array}$ & $\begin{array}{l}\text { Colorless, } \\
\text { odorless }\end{array}$ \\
\hline Boiling point & $>300^{\circ} \mathrm{C}$ & & $100^{\circ} \mathrm{C}$ \\
\hline Melting point & $-18^{\circ} \mathrm{C}$ & $199^{\circ} \mathrm{C}$ & $0^{\circ} \mathrm{C}$ \\
\hline Evaporation rate & Non volatile & & \\
\hline Solubility & Insoluble in water & & \\
\hline Viscosity & $170 \mathrm{mPas}$ & & \\
\hline Hazard nature & Non toxic & & \\
\hline Surface tension & $31.07 \mathrm{mN} / \mathrm{m}$ & & $72.75 \mathrm{mN} / \mathrm{m}$ \\
\hline Interfacial tension & $62.06 \mathrm{mN} / \mathrm{m}$ & & \\
\hline Specific gravity & $0.88 \mathrm{~g} / \mathrm{cm}^{3}$ & & $0.998 \mathrm{~g} / \mathrm{cm}^{3}$ \\
\hline
\end{tabular}

density was uniform throughout the total depth of the sand deposit. Additionally, the locations of the layers corresponded to the locations of the sensors. The pore pressure transducers (PPTs) are for measuring water pressure. The details of PPT are as follows: manufacturer is GE Druck, Keller, model is PDCR 81-3478, connector is RJ12 and conditioner is SCXI1520 with SCXI-1314. Details of the lift thickness and locations of the sensors are shown in Fig. 5. Some sensors were installed outside the wall for checking the leak of LNAPL. The model parameters for tested sandy soil and soil cement are shown in Table 2 .

\section{Centrifuge testing}

After the dry sand preparation was completed, a predetermined amount of water was gradually added to the sand until the water reached the desired level (test 1). This process was conducted by slowly dripping water into a sponge that was placed on the sand surface at a corner of the strongbox. The water level was monitored using pore pressure sensors during the centrifuge spin up. A $g$-level of 30 was used in this testing, resulting in the desired $0.60-\mathrm{m}$ thickness of soil-cement in prototype scale. A stainless steel container was mounted above the containment area and was filled with $800 \mathrm{ml}$ (21600 1 in prototype) of LNAPL that was tinted a very visible dark red colour. The groundwater flow (test 2) was initiated and was allowed to reach a steady state before the LNAPL was introduced into the model. The desired flow rate of water was $15.725 \mathrm{~cm}^{3} / \mathrm{s}$. Once a steady state was achieved, a system was developed to deliver LNAPL into the containment area at a steady and controlled flow. A normally closed solenoid valve holds the LNAPL in the container. When the desired groundwater flow was achieved, the LNAPL was
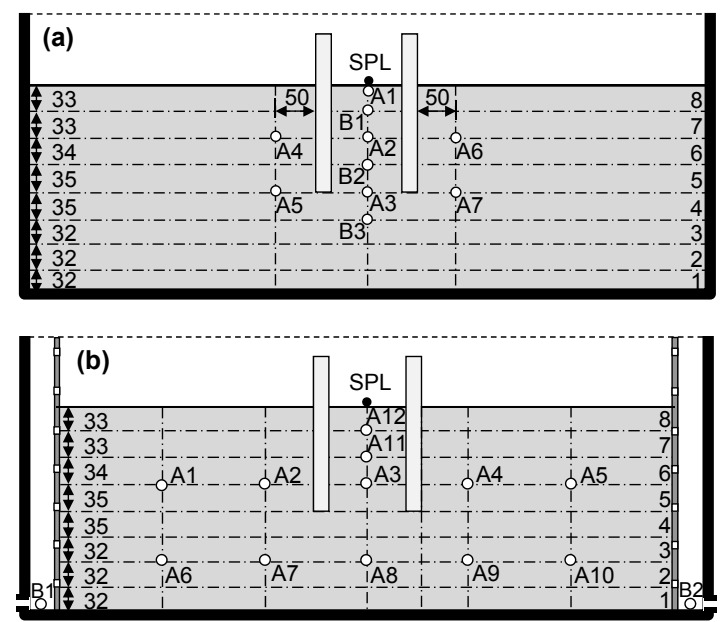

OPressure sensor (A and B) •Pressure sensor at spill point level

Fig. 5 Pressure sensor location (model unit: $\mathrm{mm}$ ): (a) no groundwater flow, and (b) groundwater flow.

released through a very small interchangeable orifice that regulates the flow at approximately $0.45 \mathrm{ml} / \mathrm{s}$ under acceleration gravity of $30 \mathrm{~g}$. The water levels in the upstream and downstream reservoir were controlled throughout testing duration of 80 days in prototype time was reached. In this study, the LNAPL migration was modelled as a $2 \mathrm{D}$ line source based on the observation during the centrifuge test.

\section{RESULTS AND DISCUSSION}

Changes in pore pressure at the different locations measured by pore pressure transducers (PPT) are shown in Fig. 6. All of the sensors which shown in Fig. 5 were located within the containment wall to investigate the behaviour of the LNAPL front movement. The other sensors located outside of the containment wall were used to determine the water level and to observe the contamination. During test 1 (no groundwater flow), the water level continuously decreased with time because of the evaporation of the water. However, the water level of test 2 (groundwater flow) remained constant because the evaporation was minimized by using the in-flight water pumping system.

Fig. 6a shows a plot of pore pressure change versus time for the condition of no groundwater flow. It shows that the LNAPL front reached A1, followed by B1 and A2 (see Fig. 3 for locations of A1, B1, and A2). Thereafter, the LNAPL plume was stable above the location of B2 (3.06 $\mathrm{m}$ in prototype depth) because there was no change in pore pressure at B2. There 
Table 2 Model parameters for tested sandy soil and soil cement.

\begin{tabular}{|c|c|c|}
\hline Description & Sandy soil & Soil cement \\
\hline \multicolumn{3}{|l|}{ Relative permeability parameters for Parker's model ${ }^{19}$} \\
\hline Limiting saturation $S_{\mathrm{m}}$ & $0.345^{(\mathrm{F} 1)}$ & $0.345^{(\mathrm{F} 1)}$ \\
\hline Fitting parameter, $n$ & $3^{(\mathrm{A})}$ & $3^{(\mathrm{A})}$ \\
\hline \multicolumn{3}{|l|}{ Capillary pressure parameters for van Genuchten's model ${ }^{20}$} \\
\hline$\lambda=m=1-1 / n$ & $0.770^{(\mathrm{C} 1)}$ & \\
\hline Residual water saturation, $S_{\mathrm{lr}}$ & $0.146^{(\mathrm{F} 2)}$ & \\
\hline $1 / P_{0}=\alpha / \rho_{\mathrm{w}} g\left(\mathrm{~Pa}^{-1}\right)$ & $3.400 \times 10^{-4(\mathrm{C} 1)}$ & \\
\hline Maximum value for capillary pressure, $P_{\max }(\mathrm{Pa})$ & $4.215 \times 10^{-4(\mathrm{M})}$ & \\
\hline Saturated water saturation, $S_{\mathrm{ls}}$ & $1^{(\mathrm{F} 2)}$ & \\
\hline \multicolumn{3}{|l|}{ Capillary pressure parameters for Parker's model ${ }^{19}$} \\
\hline Limiting saturation, $S_{\mathrm{m}}$ & & $0^{(\mathrm{F} 2)}$ \\
\hline Fitting parameter, $n$ & & $2.068^{(\mathrm{F} 2)}$ \\
\hline Strength parameter for air-NAPL, $\alpha_{\mathrm{an}}=\alpha \beta_{\mathrm{an}}$ & & $0.330^{(\mathrm{C} 2)}$ \\
\hline Strength parameter for NAPL-water, $\alpha_{\mathrm{nw}}=\alpha \beta_{\mathrm{nw}}$ & & $0.217^{(\mathrm{C} 2)}$ \\
\hline
\end{tabular}

Strength parameter is the parameter describing the shape of the saturation-capillary head curve. $\alpha$ is a curve fitting parameter; $\beta_{\mathrm{an}}\left(=\sigma_{\mathrm{aw}} / \sigma_{\mathrm{an}}\right)$ is the scaling factor for air-NAPL; $\beta_{\mathrm{nw}}\left(=1 /\left(1-1 / \beta_{\mathrm{an}}\right)\right)$ is the scaling factor for NAPLwater; (F1) is the curve fitting parameter of $k$-function curve; (F2) is the curve fitting parameter of S-P curve; (A) is recommended by Ref. 21; (C1) is calculated from van Genuchten's curve fitting parameter $(n)$; $(\mathrm{M})$ is measured from a suction test by Ref. 22; (C2) is calculated from a fitting parameter multiplied by a scaling factor ${ }^{21}$.
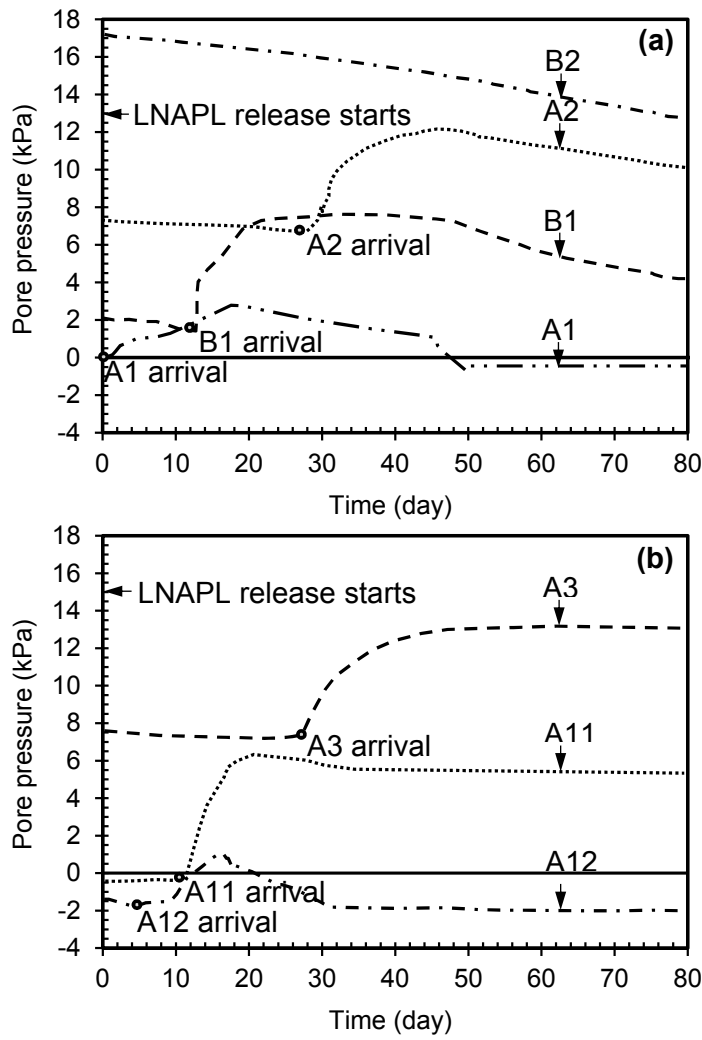

Fig. 6 Changes in pore water measured by PPT as a function of time: (a) test 1 , and (b) test 2 (prototype unit). was no LNAPL movement through the wall, which indicates that the wall can be used effectively as an LNAPL containment barrier. For this case, the depth of the wall below the water level was also judged to be adequate, as the LNAPL did not migrate underneath the wall.

Test 2 was performed to simulate groundwater flow by controlling the water level upstream and downstream throughout testing. In this test, the water level at the high-pressure side located near the soilcement wall was $6.43 \mathrm{~cm}$ below the ground surface, (Fig. 3), which resulted in a water pressure similar to that used in test 1 . Fig. $6 \mathrm{~b}$ illustrates a plot of pore pressure change versus time for groundwater flow conditions. This plot shows that the LNAPL front reached $\mathrm{A} 11$, followed by $\mathrm{A} 12$ and $\mathrm{A} 3$. In addition, the LNAPL plume migrated underneath the wall on the low-pressure side. In this case, the depth of the wall was not adequate. The reason for increasing the pore pressure after a certain time at the observed location as shown in Fig. $6 \mathrm{a}$ and Fig. $6 \mathrm{~b}$ was that the large of LNAPL depress on the sensors increasing the pore water pressure.

Fig. 7 shows pictures of the LNAPL distribution at the end of both tests. The LNAPL concentration was determined using an image processing technique $^{4,5,23,24}$. To obtain plots of LNAPL concentration, Photoshop CS3 and Surfer8 were used to measure the intensity of grey values and to show 2D plots, 

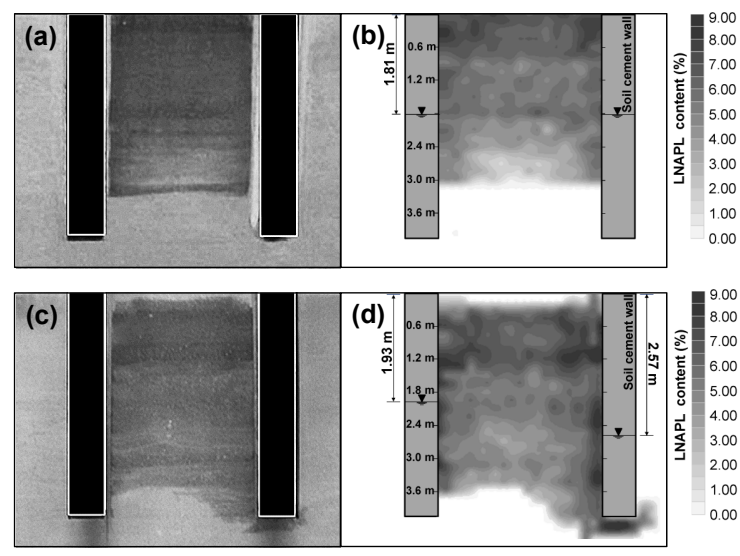

Fig. $72 \mathrm{D}$ plots of the distribution of LNAPL plume migration at the end of tests: (a) centrifuge test for test 1 , (b) image analysis for test 1 , (c) centrifuge test for test 2 , and (d) image analysis for test 2 .

respectively. The results from both tests confirmed that soil-cement barriers can be used as a containment because LNAPL cannot migrate through soil-cement walls. The LNAPL plume migration of test 1 is shown in Fig. 7a-b. The LNAPL plume migrated with a symmetrical plume distribution, but in this case, the depth of the wall was adequate for confining LNAPL migration due to the higher water level. The front of the LNAPL plume remained stable at the depth of $1.25 \mathrm{~m}$ below the initial water level. The LNAPL plume migration of test 2 is shown in Fig. 7c-d. The LNAPL plume migrated with an asymmetric plume distribution due to groundwater flow. The LNAPL level at the higher pressure side of the model remained above the tip of the wall, whereas the LNAPL plume migrated underneath the wall at the lower pressure side of the model. The front of the LNAPL plume is not more than $1.00 \mathrm{~m}$ below the wall tip. The depression of water table was found to be larger in the case of groundwater flow due to an advection effect. These results indicate that the depths of the soil cement walls below the groundwater level should be no less than $1.50 \mathrm{~m}$ for no groundwater flow and $2.50 \mathrm{~m}$ for groundwater flow.

The plumes of LNAPL movement at various times were captured with video recording. Perimeters of the plume were extracted from the images to determine the depth of the LNAPL front movement in the vertical direction at the centerline and near the walls. Fig. 8 illustrates the relationships of the locations of vertical LNAPL movement versus prototype times. Fig. 8a shows that the LNAPL moves symmetrically downward. The movement of LNAPL near the walls
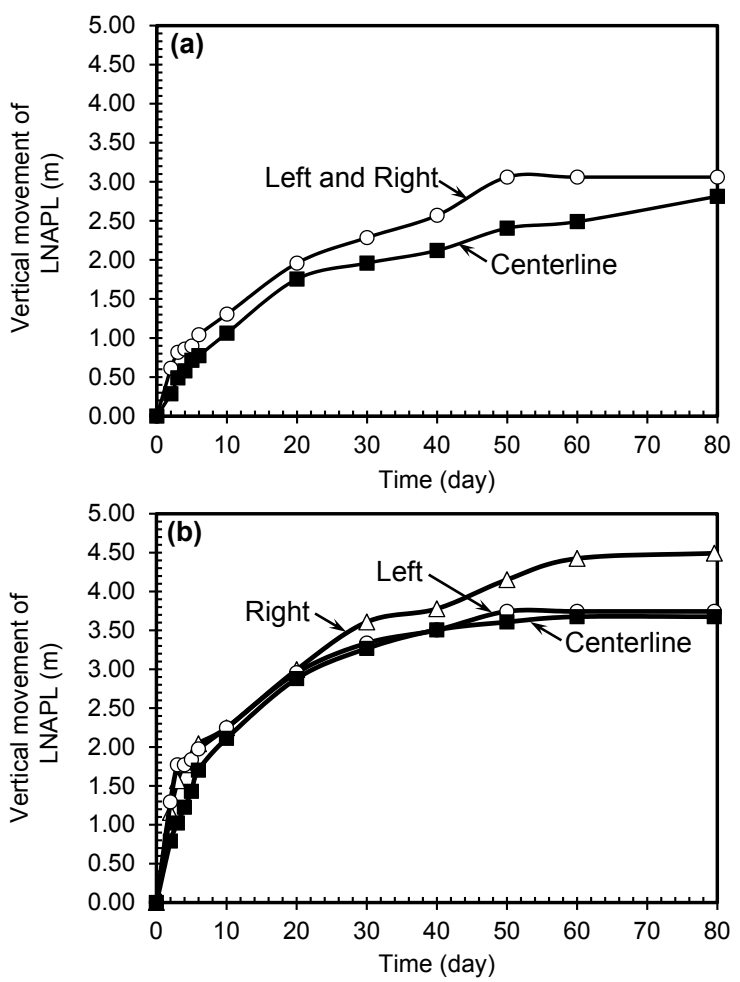

Fig. 8 Comparison of LNAPL movement at centerline of containment and near the wall on left and right direction: (a) no groundwater flow, and (b) groundwater flow.

was slightly faster than the movement at the centerline and eventually it was stable at the same level. Because the soil-cement has a suction larger than sandy soil, the voids near the wall are more continuous than at the centerline. Hence LNAPL can flow slightly faster than the centerline. Fig. $8 \mathrm{~b}$ shows that the LNAPL moves asymmetrically downward. The LNAPL near the wall at the low-pressure side migrated faster than the LNAPL near the wall at the high-pressure side. As a result, the groundwater flow affects the behaviour of LNAPL migration.

Fig. 9 presents the comparison of plume velocity in the vertical direction. This plot illustrates the effect of groundwater flow on the vertical velocity of the LNAPL movement. It shows a similarity in velocity of the LNAPL in both cases until $0.5 \mathrm{~m}$ depth because this level is higher than the water level. Hence the water pressure has no effect to velocity. In addition, a comparison of the LNAPL velocities from the image processing technique and those measured by PPT is presented. This comparison indicates that the velocity of plume movement decreases with depth and time in both tests. Additionally, the plume velocity in the 


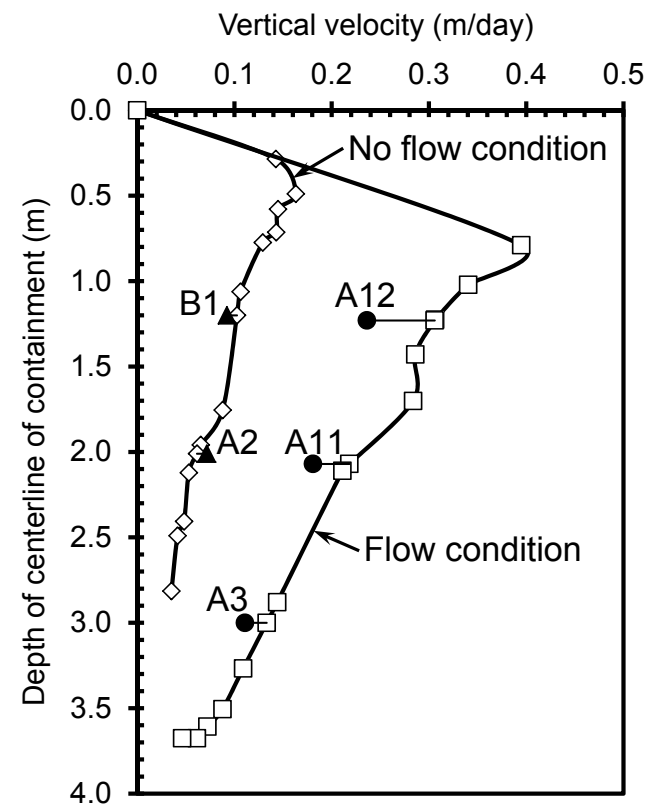

Fig. 9 Comparison of LNAPL plume velocity.

case of groundwater flow was faster than in the case of no groundwater flow at the same location. Because the increased hydraulic gradient affects the pressure head difference increased for the case of ground water flow, LNAPL will migrate along to the direction of the water flow. Furthermore, the plume velocities obtained from PPT measurement were similar to those obtained from the image processing technique. The difference observed from A12 was due to the asymmetrical movement of the LNAPL, as the sensor was located near the centerline of the model but the images were taken at the side.

\section{CONCLUSIONS}

Two centrifuge modelling experiments were performed to study the behaviour of LNAPL migration through soil-cement barriers. Of the two cases studied were groundwater-flow and no-groundwaterflow conditions. The results obtained showed that groundwater flow affects the behaviour of LNAPL plume migration. In the case of no groundwater flow, the movement of LNAPL near the walls was slightly faster than the movement at the centerline. In the case of groundwater flow, the LNAPL migrates faster and deeper due to the flow of water. As a result, the depth of the wall should be designed to account for groundwater flow effects. This study verifies that soil-cement barriers of adequate thickness can be used effectively as a containment barrier because LNAPL cannot migrate through them. The depth of
LNAPL-plumes migration was observed after the end of experiments. It is recommended that the depth of the soil-cement barrier below the groundwater level be no less than $1.50 \mathrm{~m}$ and $2.50 \mathrm{~m}$ at the low-pressure side for no-groundwater-flow conditions and groundwaterflow conditions, respectively. This study also shows that digital image processing is a valuable technique useful for the interpretation of LNAPL movement.

Acknowledgements: The authors thank the Office of the Higher Education Commission, Thailand and Rajamangala University of Technology Rattanakosin for providing funding for this study. Furthermore, thanks are due to staffs of RPI centrifuge lab for their help with the model design and testing.

\section{REFERENCES}

1. Arulanandan K, Thompson PY, Kutter BL, Meegoda NJ, Muraleetharan KK, Yogachandran C (1988) Centrifuge modeling of transport processes for pollutants in soil. J Geotech Eng 114, 185-205.

2. Illangasekare TH, Znidarcic M, Al-Sheridda M, Reible DD (1991) Multiphase flow in porous media. In: Proceedings of Centrifuge 91, Balkema, Rotterdam, The Netherlands, pp 517-23.

3. Esposito G, Allersma HGB, Selvadurai APS (1999) Centrifuge modeling of LNAPL transport in partially saturated sand. $J$ Geotech Geoenviron Eng 125, 1066-71.

4. Soga K, Kawabata J, Kechavarzi C, Coumoulos H, Waduge WAP (2003) Centrifuge Modeling of Nonaqueous Phase Liquid Movement and Entrapment in Unsaturated Layered Soils. J Geotech Geoenviron Eng 129, 173-82.

5. Allersma HGB, Esposito GM (2000) Optical analysis of pollution transport in geotechnical centrifuge tests. In: Proceedings of the International Symposium on Physical Modelling and Testing in Environmental Geotechnics, La Baule, France, pp 3-10.

6. Lo IMC, Hu LM, Meegoda JN (2004) Centrifuge modeling of light nonaqueous phase liquids transport in unsaturated soils. J Geotech Geoenviron Eng 130, 535-9.

7. Hu LM, Lo IMC, Meegoda JN (2006) Centrifuge testing of LNAPL migration and soil vapor extraction for soil remediation. Pract Periodical Hazard Toxic Radioactive Waste Manag 10, 33-40.

8. Cooke AB, Mitchell RJ (1991) Physical modeling of a dissolved contaminant in an unsaturated sand. Can Geotech J 28, 829-33.

9. Mitchell RJ, Stratton BC (1994) LNAPL penetration in porous media. In: Proceedings of the International Conference CENTRIFUGE 94, Singapore, pp 345-9.

10. Culligan-Hensley PJ, Sanvvidou C (1995) Environmental geomechanics and transports process. In: Taylor 
RN (ed) Geotechnical Centrifuge Technology, Blackie Academic, London, pp 196-263.

11. Barry DA, Griffioen JW, Li L, Lisle IG, Parlange JY, Prommer H, Sander GC (2001) Similitude applied to centrifugal scaling of unsaturated flow. Water Resour Res 37, 2471-9.

12. Taylor RN (1995) Geotechnical Centrifuge Technology, Blackie Academic and Professional, London.

13. Nakajima H, Hirooka A, Takemura J, Marino MA (1998) Centrifuge modeling of one dimensional subsurface contamination. J Am Water Resour Assoc 34, 1415-25.

14. Rezzoug A, Diethard K, Triantafyllidis T (2002) Scaling laws for centrifuge modeling of capillary rise in sandy soils. J Geotech Geoenviron Eng 130, 615-20.

15. Kumar PR (2007) Scaling laws and experimental modeling of contaminant transport mechanism through soils in a geotechnical centrifuge. Geotech Geol Eng 25, 581-90.

16. Nicholson PJ, Jasperse BH, Fisher MJ (1997) Economical alternatives for containment barriers. In: International Containment Technology Conference \& Exhibit, St. Petersburg, Florida.

17. Kamon M, Li Y, Flores G, Inui T, Katsumi T (2006) Experimental and numerical study on migration of LNAPL under the influence of fluctuating water table in subsurface. Annuals Disast Prev Res Inst Kyoto Univ 49 B, 383-92.

18. Sripongphichit W (2006) Investigation of fossil fuel contamination in unsaturated zone using digital image analysis. MEng thesis, Univ of Kasetsart, Bangkok, Thailand.

19. Parker JC, Lenhard RJ, Kuppusamy T (1987) A parametric model for constitutive properties governing multiphase flow in porous media. Water Resour Res $\mathbf{2 3}$, 618-24.

20. van Genuchten MT (1980) A closed-form equation for predicting the hydraulic conductivity of unsaturated soils. Soil Sci Soc Am J 44, 892-8.

21. Rasmusson K, Rasmusson M (2009) NAPL spill modeling and simulation of pumping remediation. MSc thesis, Uppsala Univ, Uppsala, Sweden.

22. Rungruang S, Kererat C (2010) Contaminant migration behavior through soil cement barrier under full scale test, Res Rep 2010, Institute for Research and Development, Rajamangala Univ of Technology Rattanakosin, Nakorn Pathom, Thailand.

23. Pan T (2002) Fine aggregate characterization using digital image analysis. MSc thesis, LSU, Baton Rouge, LA.

24. Esposito GM, Allersma HGB, Soga K, Kechavarzi C, Coumoulos H (2000) Centrifuge simulation of LNAPL infiltration in partially saturated porous granular medium. In: Proceedings of the International Symposium on Physical Modelling and Testing in Environmental Geotechnics, La Baule, France, pp 141-8. 